\title{
RETROPERITONEAL TERATOMA IN INFANCY: A RARE CASE
}

\author{
Sachin Khanduri', Fahimul Huda², Girjesh Kumar ${ }^{3}$, Parul Shokeen ${ }^{4}$, Tarim Usmani 5
}

1 Professor and HOD, Department of Radiodiagnosis, Era's Lucknow Medical College and Hospital.

2Junior Resident, Department of Radiodiagnosis, Era's Lucknow Medical College and Hospital.

3Junior Resident, Department of Radiodiagnosis, Era's Lucknow Medical College and Hospital.

4Junior Resident, Department of Radiodiagnosis, Era's Lucknow Medical College and Hospital.

5Junior Resident, Department of Radiodiagnosis, Era's Lucknow Medical College and Hospital.

\section{ABSTRACT}

Teratomas are congenital tumours arising from all three germ cell layers. Retroperitoneal teratoma is very uncommon in the infant age group. Patient commonly presents with progressive abdominal distension and intra-abdominal lump. Teratomas comprises of third most common type of retroperitoneal neoplasm seen in infants and children after Wilms' tumour and neuroblastoma. We hereby report a case of a giant retroperitoneal teratoma in an infant. A 3-month-old female child was admitted with complaint of abdominal distension. Abdominal USG and CT scan revealed a tumour suggestive of retroperitoneal teratoma. Intraoperative finding revealed a large retroperitoneal tumour occupying mainly the whole of the abdomen. Resection of tumour was done successfully.

\section{KEYWORDS}

Retroperitoneal, Teratoma, Infancy.

HOW TO CITE THIS ARTICLE: Khanduri S, Huda F, Kumar G, et al. Retroperitoneal teratoma in infancy: a rare case. J. Evolution Med. Dent. Sci. 2016;5(64):4602-4605, DOI: 10.14260/jemds/2016/1049

\section{INTRODUCTION}

Teratomas are germ cell tumours that arise from more than one germ cell layer.1-4 They are a result of uncontrolled proliferation of pluripotent germ cells. They can be congenital or acquired. Gonads are the most common site. ${ }^{1}$ Though less commonly, they can occur at extragonadal locations like sacrococcygeal, mediastinal, retroperitoneal and pineal gland.2,3,4 These extragonadal sites are more commonly involved in infant and children. ${ }^{5}$ Infants and children usually present with abdominal lump leading to abdominal distension. Retroperitoneal teratoma in infancy can pose diagnostic difficulty with other intra-abdominal tumours in this age group like Wilms' tumour, neuroblastoma. Here, we present a rare case of retroperitoneal teratoma in a 3-month-old female infant.

\section{CASE REPORT}

We hereby report a case of a giant retroperitoneal teratoma in an infant. A 3-month-old female child was admitted with complaints of abdominal distension.

The patient was admitted with complaints of slowly progressive abdominal distension since 1 month. She also had frequent episodes of vomiting, poor feeding and respiratory distress. Family or past medical history was not significant. Her abdominal examination revealed an irregular firm abdominal mass in left lumbar and iliac area. The remainder of the examination was not significant.

Routine blood tests and urinalysis were within normal limits. Serum electrolytes, renal function tests and liver function tests were within normal limits.

Financial or Other, Competing Interest: None.

Submission 24-04-2016, Peer Review 26-07-2016,

Acceptance 01-08-2016, Published 11-08-2016.

Corresponding Author:

Dr. Fahimul Huda,

Era's Lucknow Medical College and Hospital,

PG Boy's Hostel, Room No. D22, Sarfarazgani,

Lucknow-226003, Uttar Pradesh.

E-mail: fahim.huda@gmail.com

DOI: 10.14260/jemds/2016/1049
Abdominal USG and CT scan revealed a tumour suggestive of retroperitoneal teratoma. Intraoperative finding revealed a large retroperitoneal tumour occupying mainly the whole of the abdomen. Resection of tumour was done successfully.

\section{ULTRASOUND}
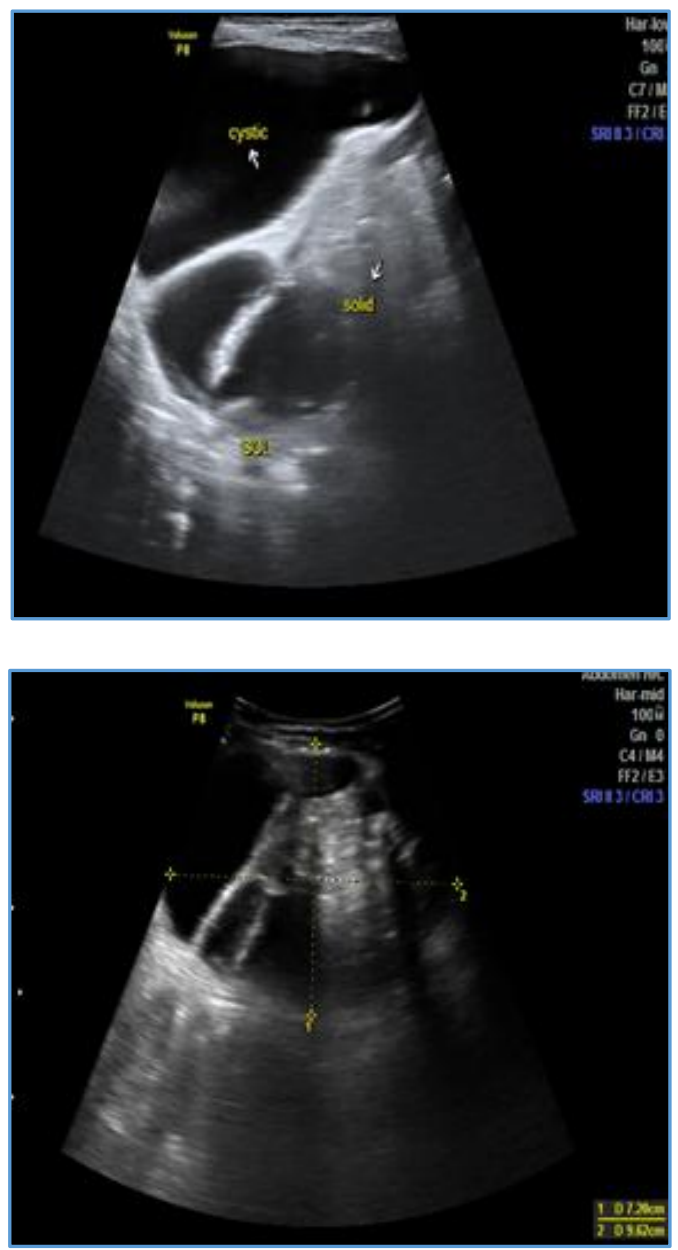

Large Heteroechoic Lesion with Multiple Cystic Spaces and Septations with Few Echogenic Foci 
Ultrasound whole abdomen was done, which revealed a large heteroechoic lesion in the peritoneal cavity on left side with multiple cystic spaces and septations. A few echogenic foci were noted within the space occupying lesion with posterior acoustic shadowing suggestive of calcifications. A few calcific foci and fatty tissues were noted within the lesion with lateral displacement of the left kidney.

\section{CONTRAST-ENHANCED COMPUTED TOMOGRAPHY}
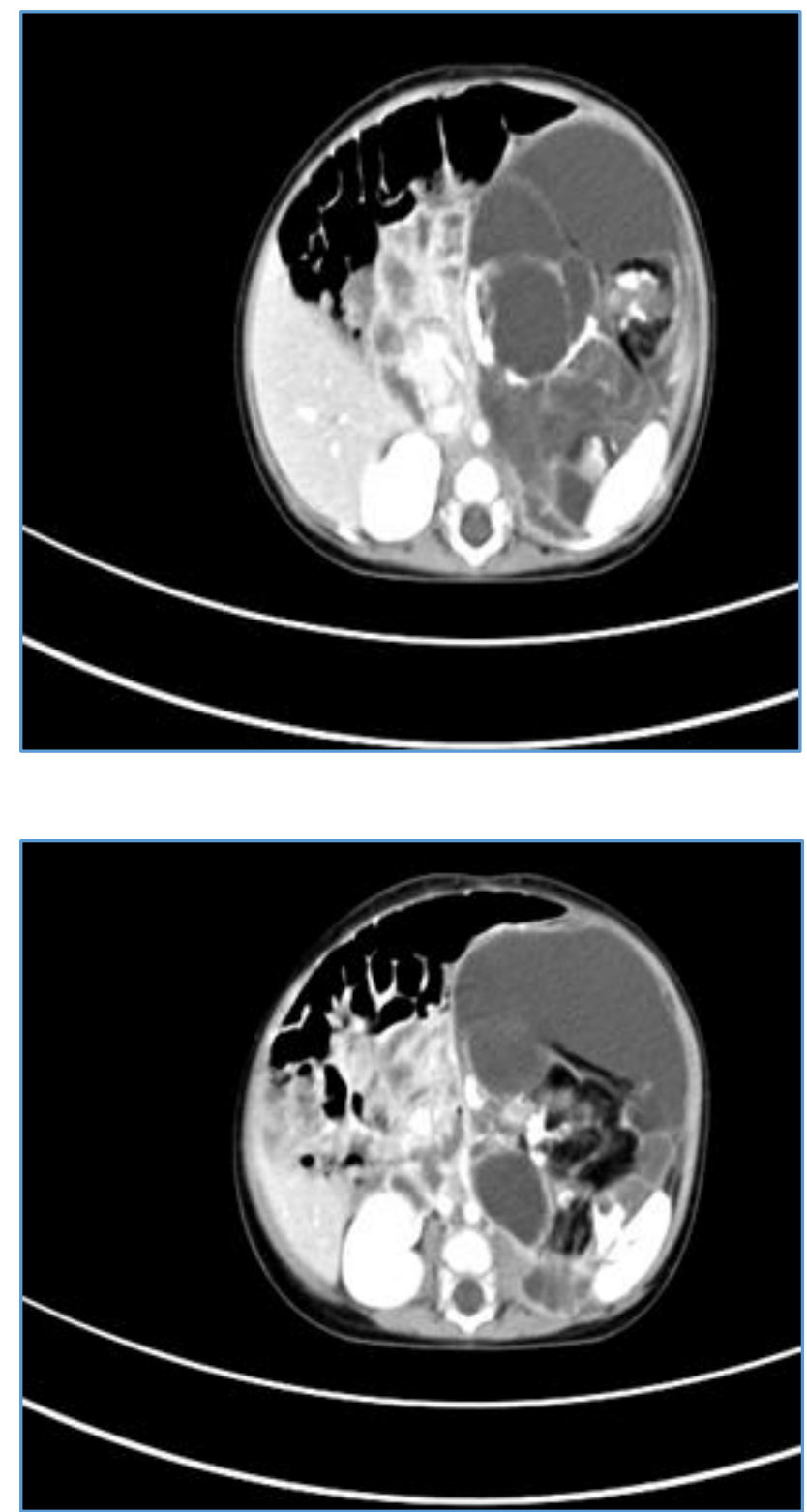

A Large Retroperitoneal Space Occupying Lesion of Mixed Attenuation

Contrast enhanced computed tomography of abdomen revealed a large retroperitoneal space occupying lesion of mixed attenuation with multiple cystic spaces and thick septations as well as multiple areas of fatty attenuation with coarse calcification within it.

The mass is causing displacement of left kidney posterolaterally and bowel loops medially to right side with encasement of multiple vessels.
MRI
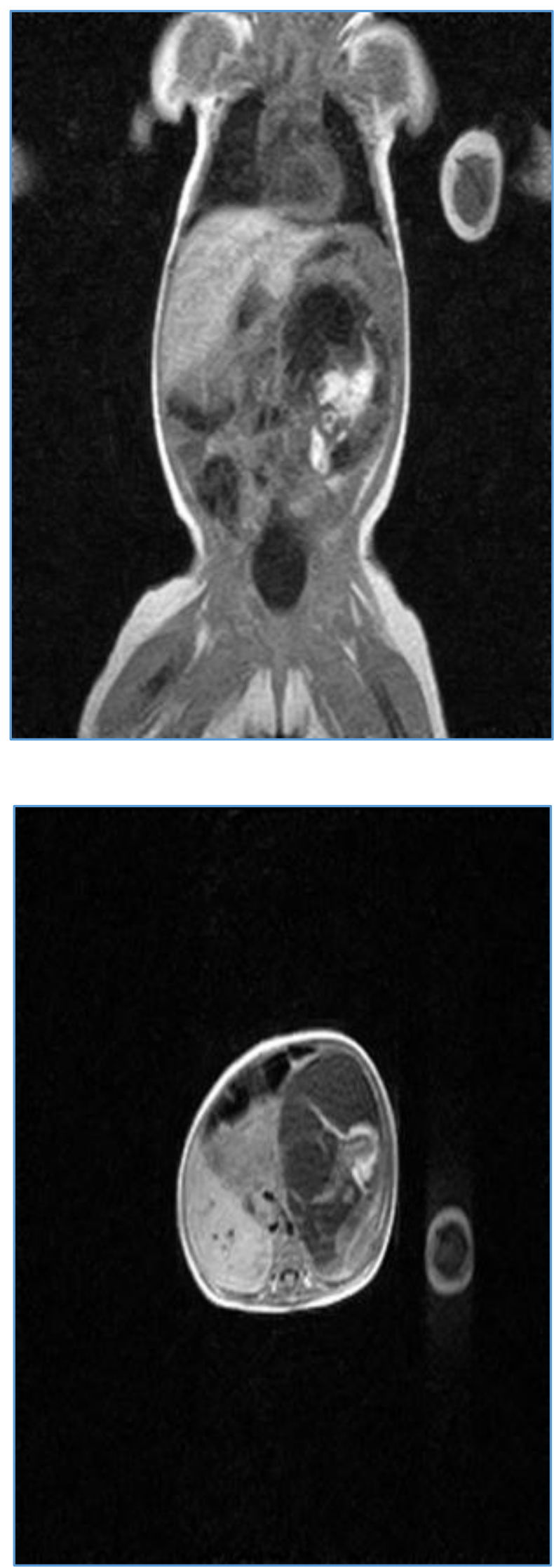

A Large Retroperitoneal Mass showing Heterogeneous Signals of Fluid, Soft Tissue, Fat and Calcification Noted 
Then magnetic resonance imaging of the patient was done, which showed a large retroperitoneal mass with heterogeneous signals of fluid, soft tissue, fat and calcification and causing displacement of viscera laterally. Provisional diagnosis of retroperitoneal teratoma was made.

\section{OPERATIVE PHOTOGRAPH OF RETROPERITONEAL TERATOMA}

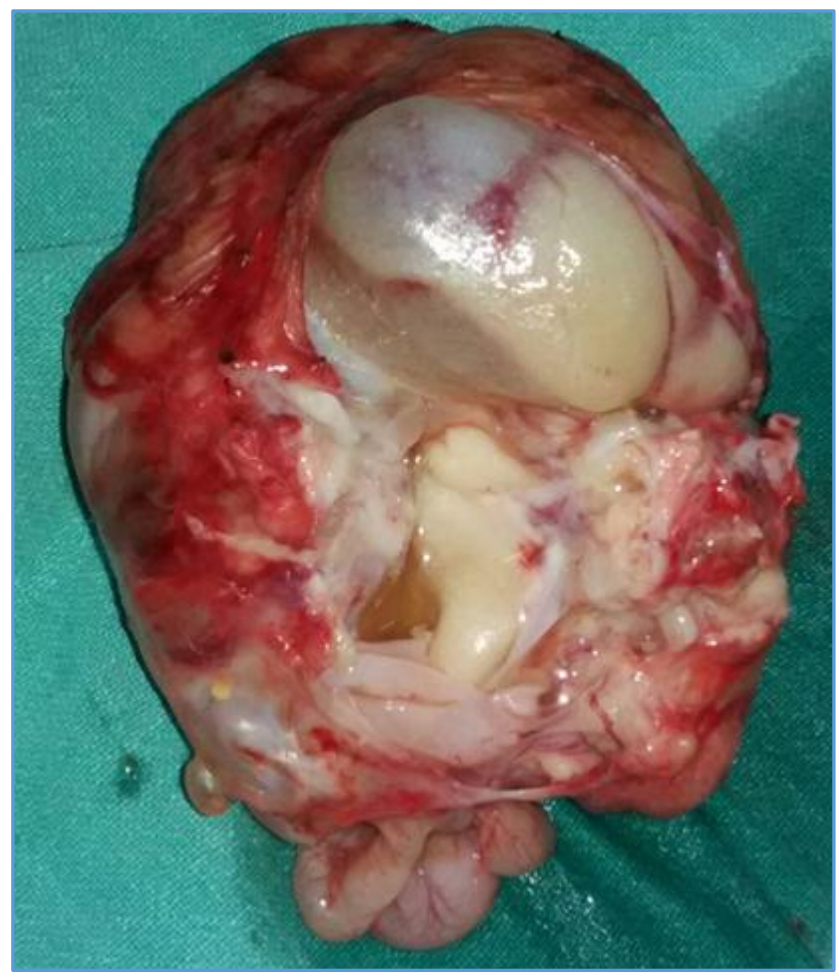

Intraoperative finding revealed a large retroperitoneal tumour comprising of both solid and cystic areas occupying mainly the left and central abdomen.

Tumour was adherent to the adjacent structures. Complete radical excision of tumour was done and specimen was sent for histopathological examination.

Histopathological examination showed both cystic and solid components, predominantly cystic.

The cysts contained hair, grumous material and serous liquid mainly. Also there were foci of calcification, bone, cartilage and teeth.

\section{DISCUSSION}

- Teratomas are germ cell tumours arising from more than one germ cell layer.1-4 They result from faulty migration of pluripotent germ cells from yolk sac or endoderm to genital ridge during foetal development. 6

- Retroperitoneal teratomas comprises of $3.5-4 \%$ of all germ cell tumours in children and $11 \%$ of primary retroperitoneal neoplasms. ., 8 It is the third most common type of retroperitoneal neoplasm in infant and children after Wilms' tumour and neuroblastoma. ${ }^{9}$

- Germ cell tumours can be congenital or acquired. Gonads are the most common site. ${ }^{1}$ Extragonadal sites are less commonly involved. ${ }^{5}$ Retroperitoneum is one of the common extragonadal location for teratoma.2,3,4 Retroperitoneal teratoma are more common in infancy and children with male predilection. ${ }^{5}$ In our case, teratoma has been reported in a female infant involving retroperitoneum, which is relatively rare. Due to their location, they are usually identified after they grow to huge proportions. ${ }^{9}$

- Teratomas can be classified into mature and immature teratoma. Mature teratomas can be solid-cystic, have more of mature tissue and are usually benign. ${ }^{10}$ Immature teratomas have more of solid component and undifferentiated immature tissue and are more likely to be malignant. ${ }^{10}$

- Clinical basis alone cannot help in making the final diagnosis of teratoma. Radiological findings help in diagnosing retroperitoneal teratoma. Plain X-ray can help in identifying calcification. Ultrasound of abdomen helps in identifying solid and cystic components and is usually the first imaging modality used in paediatric abdominal mass. Computed tomography and magnetic resonance imaging further helps in identifying the extent of the disease in retroperitoneum, involvement of surrounding structures, better appreciation of the contents of teratoma like the fatty component, calcification areas and cystic-solid areas. ${ }^{10}$ Magnetic resonance imaging further helps in better appreciation of soft tissue and extent of lesion. 10

- Review of literature shows that internal homogeneity, fat density, cyst formation and calcification to be the important predictors of benign retroperitoneal teratoma on CT scan. 11

- These infants usually present with a large lump in abdomen leading to abdominal distension. As in our case also, the patient came with abdominal distention. Teratomas in this age group and retroperitoneal location can pose diagnostic difficulty with other intra-abdominal tumours in this age group like Wilms' tumour and neuroblastoma. Imaging findings help in diagnosing retroperitoneal teratoma.

- Prognosis of retroperitoneal teratoma in infancy depends on the complete resectability of the tumour. ${ }^{12}$ Complete surgical resection of the tumour is associated with good prognosis and long-term survival rate. ${ }^{12}$ As in our case, the tumour was completely resected successfully and the patient at present is disease free with no complications.

\section{CONCLUSION}

Retroperitoneal teratoma is a rare condition occurring more commonly in infants and children. Radiological findings play a crucial role in diagnosing this rare entity. The tumour is amenable to curative surgical excision, which offers good prognosis.

\section{REFERENCES}

1. Horton Z, Schlatter M, Schultz S. Pediatric germ cell tumors. Surg Oncol 2007;16(3):205-13.

2. McKenney JK, Heerema-McKenney A, Rouse RV. Extragonadal germ cell tumors: a review with emphasis on pathologic features, clinical prognostic variables and differential diagnostic considerations. Adv Anat Pathol 2007;14(2):69-92.

3. Ueno T, Tanaka YO, Nagata M, et al. Spectrum of germ cell tumors: from head to toe. Radiographics 2004;24(2):387404.

4. Schmoll HJ. Extragonadal germ cell tumors. Ann Oncol 2002;13(Suppl 4):S265-72.

5. Hui JPK, Luk WH, Siu CW, et al. Teratoma in the region of an adrenal gland in a 77 year old man. Journal of the Hong Kong College of Radiologists 2004;7(4):206-9. 
6. Choyke PL, Hayes WS, Sesterhenn IA. Primary extragonadal germ cell tumors of the retroperitoneum: differentiation of primary and secondary tumors. Radiographics 1993;13(6):1365-75.

7. Grosfeld JL, Ballantine TV, Lowe D, et al. Benign and malignant teratomas in children: analysis of 85 patients. Surgery 1976;80(3):297-305.

8. Nguyen CT, Kratovil T, Edwards MJ. Retroperitoneal teratoma presenting as an abscess in childhood. J Pediatr Surg 2007;42(11):21-3.
9. Gatcombe HG, Assikis V, Kooby D, et al. Primary retroperitoneal teratomas: a review of the literature. J Surg Oncol 2004;86(2):107-13.

10. Mathur P, Lopez-Viego MA, Howell M. Giant primary retroperitoneal teratoma in an adult: a case report. Case Reports In Medicine Article ID- 650424, 2010:1-3.

11. Hayasaka K, Yamada T, Saitoh Y, et al. CT evaluation of primary benign retroperitoneal tumor. Radiat Med 1994;12(3):115-20.

12. Amit C, Samir M, Ashish W, et al. Retroperitoneal teratomas in children. Indian J Pediatr 2006;73(3):221-3. 